\title{
Exploring miR-9 Involvement in Ciona intestinalis Neural Development Using Peptide Nucleic Acids
}

\author{
Silvia Mercurio ${ }^{1}\left(\mathbb{D}\right.$, Silvia Cauteruccio $^{2, *}{ }^{\mathbb{C}}$, Raoul Manenti ${ }^{1}\left(\mathbb{D}\right.$, Simona Candiani ${ }^{3, *}{ }^{\mathbb{C}}$, \\ Giorgio Scarì ${ }^{4}$, Emanuela Licandro ${ }^{2}$ and Roberta Pennati ${ }^{1}$ \\ 1 Department of Environmental Science and Policy, Università degli Studi di Milano, 20133 Milano, Italy; \\ Silvia.Mercurio@unimi.it (S.M.); raoul.manenti@unimi.it (R.M.); roberta.pennati@unimi.it (R.P.) \\ 2 Department of Chemistry, Università degli Studi di Milano, 20133 Milano, Italy; emanuela.licandro@unimi.it \\ 3 Department of Earth Science, Environment and Life, Università degli Studi di Genova, 16132 Genova, Italy \\ 4 Department of Biosciences, Università degli Studi di Milano, 20133 Milano, Italy; giorgio.scari@unimi.it \\ * Correspondence: silvia.cauteruccio@unimi.it (S.C.); candiani@unige.it (S.C.); Tel.: +39-0250314147 (S.C.); \\ $+39-0103538051$ (S.C.)
}

Received: 27 February 2020; Accepted: 13 March 2020; Published: 15 March 2020

check for updates

\begin{abstract}
The microRNAs are small RNAs that regulate gene expression at the post-transcriptional level and can be involved in the onset of neurodegenerative diseases and cancer. They are emerging as possible targets for antisense-based therapy, even though the in vivo stability of miRNA analogues is still questioned. We tested the ability of peptide nucleic acids, a novel class of nucleic acid mimics, to downregulate miR-9 in vivo in an invertebrate model organism, the ascidian Ciona intestinalis, by microinjection of antisense molecules in the eggs. It is known that miR-9 is a well-conserved microRNA in bilaterians and we found that it is expressed in epidermal sensory neurons of the tail in the larva of $C$. intestinalis. Larvae developed from injected eggs showed a reduced differentiation of tail neurons, confirming the possibility to use peptide nucleic acid PNA to downregulate miRNA in a whole organism. By identifying putative targets of miR-9, we discuss the role of this miRNA in the development of the peripheral nervous system of ascidians.
\end{abstract}

Keywords: PNA; antisense therapy; invertebrate; nervous system development; tunicates; microRNA

\section{Introduction}

The microRNAs (miRNAs) are small (19-25 nucleotides in length) non-coding RNAs, which have emerged as a fundamental class of potent regulatory molecules [1]. They are involved in many developmental and physiological processes [2], as well as in pathological conditions. Dysregulation of miRNAs is indeed associated with a variety of pathologies [3], and the possibility to regulate gene expression by interfering with miRNA networks is one of the most intriguing fields of novel drug development (miRNA-based therapeutics); miRNAs replacement or inhibition could represent an effective therapeutic approach in many diseases [4]. Although huge advances have been made in miRNA-based therapy, the in vivo stability of miRNA analogues is still one of the main challenges in this field $[5,6]$.

In this regard, peptide nucleic acids (PNAs) are promising tools for interference with miRNA activities and restoration of normal expression of their targets [7,8]. PNAs are synthetic mimics of nucleic acids $[9,10]$, in which the negatively charged sugar-phosphate backbone is replaced by the neutral N-(2-aminoethyl)glycine unit. A set of unique features, including high specific and selective binding affinity towards complementary DNA and RNA strands [11] and enzymatic resistance [12], makes PNAs particularly suitable for antisense therapy [13]. 
At present, data on the use of PNAs to target miRNAs are accumulating [14-20], demonstrating the potential of PNA for future therapeutic applications, as well as for studying miRNA functions. However, only a few studies have been performed in vivo. In mice, PNA-based inhibition of miR-155 was demonstrated to be highly efficient and sequence-specific. In the experimental animals, treatment with anti-miR-155 PNAs did not affect levels of unrelated miRNAs, and the effects of the PNA-based inhibition mainly recapitulated the effects of miR-155 genetic deletion [21]. More recently, our research group successfully downregulated miR-7 by injections of anti-miR-7 PNAs directly into the eggs of a basal chordate, the ascidian Ciona intestinalis [22].

Ascidians are marine filter-feeding animals closely related to vertebrates. They develop through a tadpole larva, which displays a typical chordate body plan [23], and are amenable model organisms for genetics, experimental embryology, and molecular biology [23,24]. The genome of $C$. intestinalis, the most studied ascidian, retains the original form that existed before vertebrate genome duplications [25], keeping all the major vertebrate miRNA families [26]. Among these, miR-9 is a well-conserved miRNA that plays essential roles in developing and adult nervous system [27]. In Ciona robusta, previously known as C. intestinalis type A [28], miR-9 was found to be expressed at gastrula and larval stages [26]. In this species, through a transcriptome-wide study of gene expression of both mRNA and microRNA, it was found that miR-9 is upregulated during oral siphon regeneration and is involved in the differentiation of neural progenitors through regulation of the cytoskeleton and cell cycle [29]. This pro-neural function of miR-9 is conserved between ascidians and vertebrates, in which one of its key functions is to regulate the generation of postmitotic neurons from neural precursor cells [30]. In other invertebrate models, such as Drosophila melanogaster, miR-9 expression and functions are strikingly different from vertebrates, suggesting that miR-9 roles have undergone vast changes during evolution $[27,31,32]$.

In humans, miR-9 is also involved in neurodegenerative diseases and cancers. Deregulation of miR-9 levels was observed in different neural pathologies; high levels of miR-9 were found in postmortem brains of patients with Alzheimer's diseases [33], whereas miR-9 is downregulated in Huntington's diseases [34]. Altered expression of miR-9 affects brain tumors, as well as breast and colorectal cancer formation and progression [35], making this miRNA a perfect candidate in cancer therapy [36].

Thus, considering the therapeutic potential of miR-9 and the advantages of PNA-based approaches, in this study we aim to investigate the ability of a PNA specifically designed to target miR-9 to inhibit its function in vivo, using C. intestinalis as a model organism [22]. Moreover, we evaluated the effects of this inhibition on the development of the $C$. intestinalis nervous system and proposed a possible mechanism of function by identifying its putative targets. This work adds precious information about conserved functions of miR-9 in chordates.

\section{Results}

\section{1. $m i R-9$ and PNAs}

The miR-9 sequence is highly conserved among metazoans. Ciona intestinalis mature miR-9 is 20 bases long; the first 15 bases are perfectly conserved among different chordate species, as well as the last three nucleotides at the $3^{\prime}$ end. Therefore, at the $5^{\prime}$ region, the seed region appears to be evolutionarily conserved (Figure 1A).

Anti-miRNA PNAs are designed to be a perfect reverse complement to the mature miRNAs. In this study, we designed a 20-mer PNA that is complementary to miR-9-PNA-a9 (Figure 1B). Moreover, to verify the specificity of the interaction between PNA-a9 and miR-9, a scrambled anti-miR-9 PNA, PNA-sc9, was designed, which shares the same base composition with the specific sequence, however exhibited a randomized sequence (Figure 1B). PNA-a9 and PNA-sc9 were synthesized according to standard protocols for solid-phase synthesis of PNA, and the final sequences were purified by reverse phase-high pressure liquid chromatography (RP-HPLC). 
A

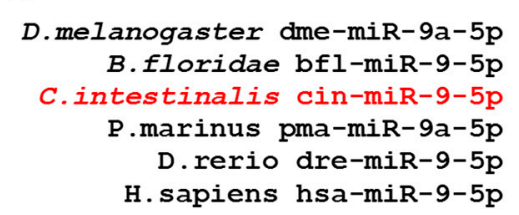

1

UCUUUGGUUAUCUAGCUGUAUGA UCUUUGGUUAUCUAGCUGUAUGUCUUUGGUUAUC---CAGUUUGA UCUUUGGUUAUCUAGCUGUAUGUCUUUGGUUAUCUAGCUGUAUGA UCUUUGGUUAUCUAGCUGUAUGA

\section{B miR-9 3'-UCUUUgGUUAUCCAGUUUGA-5' \\ PNA-a9 H-TCAAACTGGATAACCAAAGA-NH ${ }_{2}$ \\ PNA-sC9 H-AGGACAATCTAAGAACCAAT-NH ${ }_{2}$}

Figure 1. (A) Multialignment of miR-9 from different species. Identical residues are highlighted in yellow, and those conserved in at least $50 \%$ of sequences in light blue. The mature miR-9 sequences were retrieved from miRBase: dme-miR-9a-5p: MIMAT0000114; bfl-miR-9-5p: MIMAT0009465; cin-miR-9-5p: MIMAT0016396; pma-miR-9a-5p: MIMAT0019373; dre-miR-9-5p: MIMAT0001769; hsa-miR-9-5p: MIMAT0000441. (B) PNA sequences used in this study: PNA-a9 and PNA-sc9.

\section{2. miR-9 Expression during $C$. intestinalis Development}

In order to determine miR-9 expression in developing C. intestinalis embryos, we performed whole mount in situ hybridization with a specific locked nucleic acid (LNA) probe for mature Cin-miR-9 (accession: MIMAT0016396). In swimming larvae, the hybridization signal was localized in the epidermal sensory neurons of dorsal and ventral midlines of the tail (Figure 2D). These results were confirmed by in situ hybridization with a probe specific for pri-miR-9 (Figure 2A-C). In juveniles, the miR-9 signal was detectable in several cells scattered in the epidermis near the oral syphon (Figure 2E,F).

A

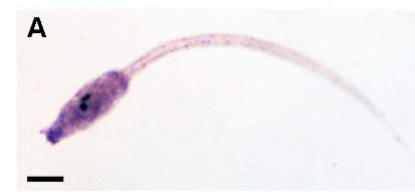

$$
\text { c }
$$

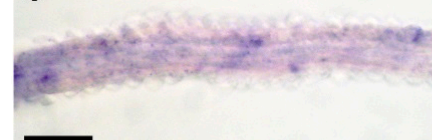

E

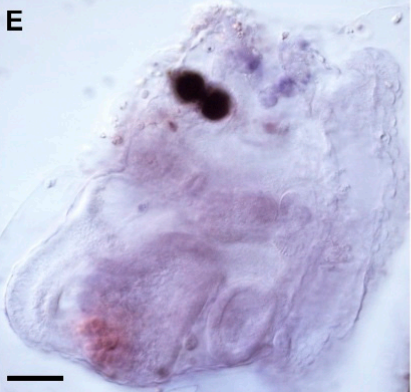

B

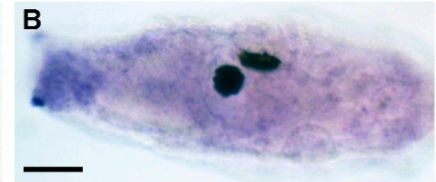

D

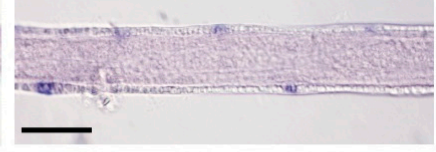

F

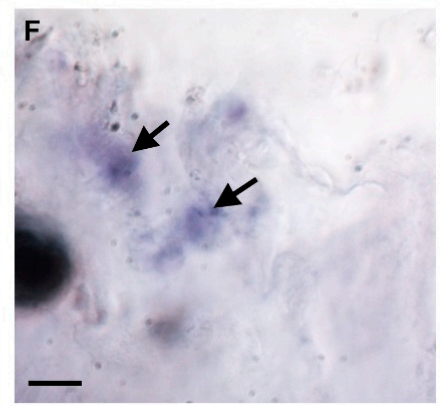

Figure 2. Whole mount in situ hybridization with pri-miR-9 (A-C) and anti-miR-9 locked nucleic acid -LNA probe (D-F) in larvae and juveniles of Ciona intestinalis. (A) Swimming larva. (B) Trunk of a larva. (C,D) Details of the tail of a swimming larva. (E) Whole mount of 5-day-old juvenile. (F) Details of the oral siphon region of a juvenile. Arrows indicate positive cells. Scale bar $=50 \mu \mathrm{m}(\mathbf{A}), 25 \mu \mathrm{m}(\mathbf{B})$, $40 \mu \mathrm{m}(\mathbf{C}, \mathbf{D}), 25 \mu \mathrm{m}(\mathbf{E}), 60 \mu \mathrm{m}(\mathbf{F})$. 


\section{3. miR-9 Downregulation by PNAs}

To investigate the role of miR-9 in development, microinjections of PNA-a9 and PNA-sc9 (used as controls) were performed in C. intestinalis eggs. No difference in the developing rates was observed between embryos microinjected with PNA-a9 (65\%) and controls injected with the medium $(72 \%)$ and with PNA-sc9 (66\%). Most of the embryos injected with PNA-a9 displayed a rounded and shorter trunk than controls (70\%). The morphology of the embryos injected with PNA-sc9 was not affected by the treatment $(78 \%)$, being comparable with the controls injected with the medium.

When we analyzed the expression of neural marker genes, PNA-a9-injected embryos showed anomalies at the level of the peripheral nervous system. Indeed, in situ hybridization with a pan neural marker, Ci-Pans [37], revealed a reduced expression in the epidermal sensory neurons of both the trunk and tail (80\%; Figure 3). Particularly, in the tail, transcripts were absent in the proximal dorsal and ventral epidermal neurons, however some neurons were eventually marked in the ventral tip of the tail (Figure 3C,D,F,G,I). Similarly, anterior sensory neurons of the trunk, including the papillary sensory neurons, were reduced in PNA-a9-injected embryos (Figure 3D,F).
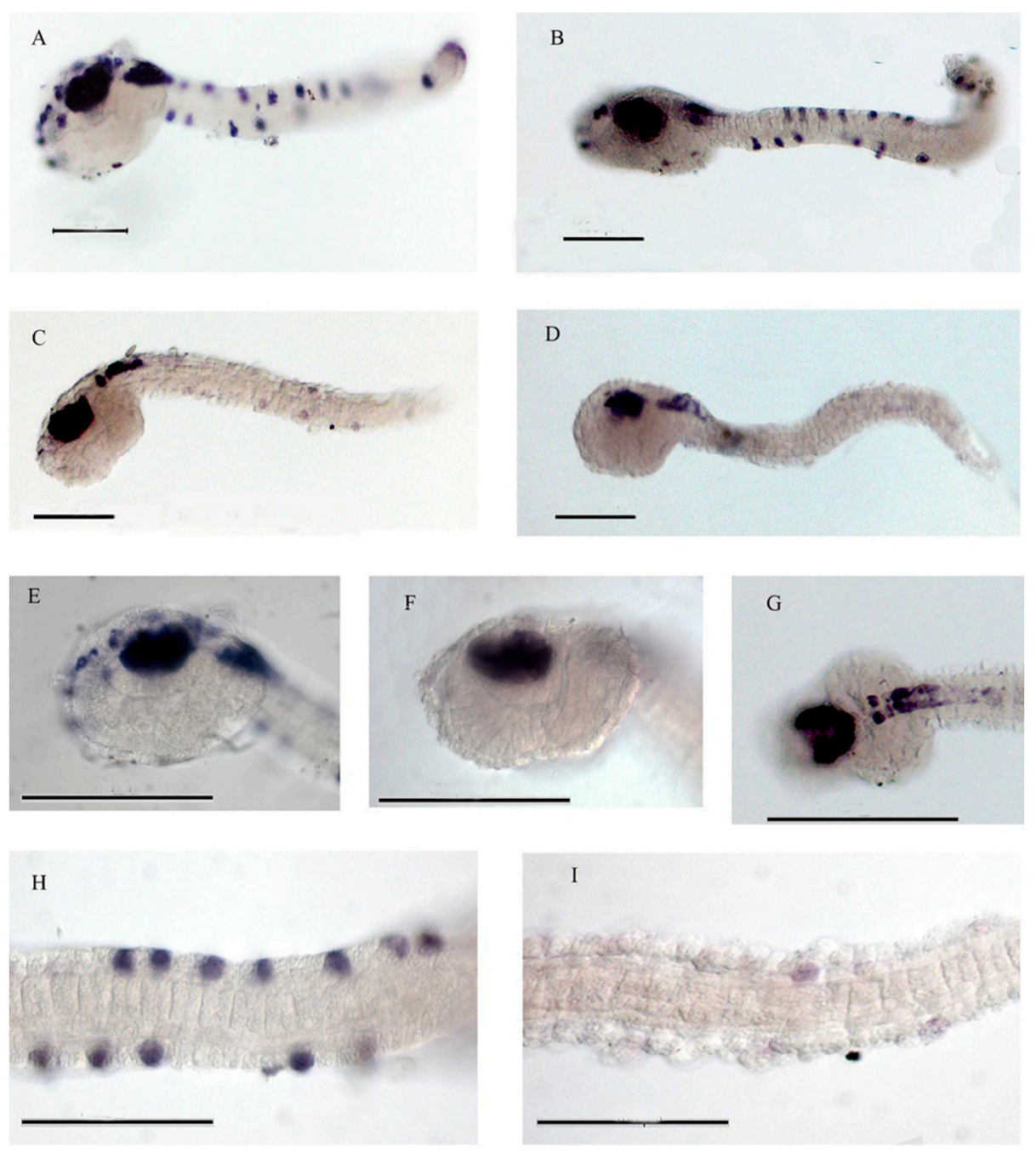

Figure 3. Whole-mount in situ hybridization with Ci-Pans probe. (A) Control and (B) PNA-sc9-injected embryos reveal similar expression. (C,D) Two lateral views of PNA-a9-injected embryos displaying a marked decrease of the signal in the epidermal sensory neurons. At higher magnification, the decrease of the signal in peripheral neurons induced by PNA-a9 is particularly evident in the trunk ((E) control; $(\mathbf{F}, \mathbf{G})$ injected samples) and tail $((\mathbf{H})$ control; (I) injected embryo). Scale bar, $100 \mu \mathrm{m}$ for all panels. 
We further characterized the effects of PNA-a9 injection; samples were processed for in situ hybridization with Ci-POU-IV and Ci-V-Glut probes. $\mathrm{Ci}-\mathrm{POU}-\mathrm{IV}$ is a gene involved in neural precursor specification and is a marker of the epidermal sensory neurons [38] (Figure 4A,B,D,E). Ci-POU-IV expression was completely absent in the tail of $80 \%$ of the larvae developed from injected eggs with PNA-a9 and only a few isolated neurons were faintly marked in the ventral midline (Figure 4C,F), confirming previous results. Ci-V-Glut [39] marks the sensory neurons of the papillae and the tail, the posterior visceral ganglion, and the posterior neural tube in the controls (Figure 4G). In injected larvae, the expression of this gene was evident only in a few neurons of the proximal neural tube, very close to the trunk $(90 \%$ of tested embryos; Figure $4 \mathrm{H})$
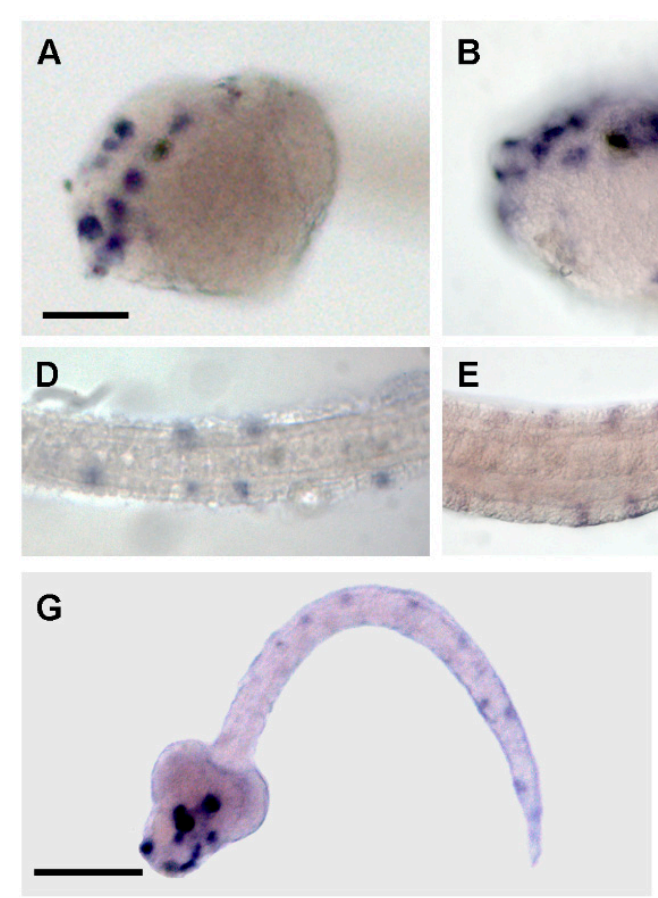
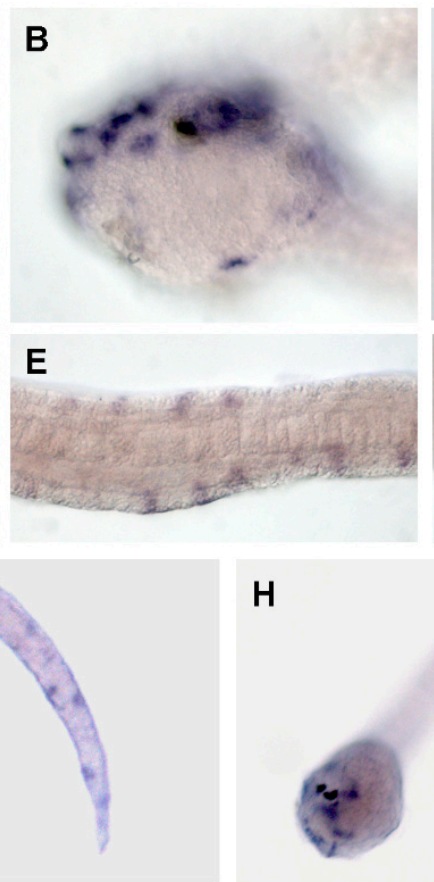
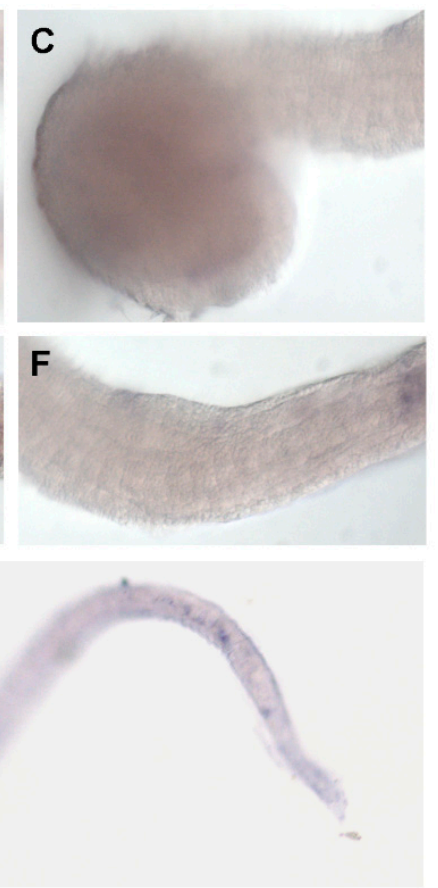

Figure 4. Whole mount in situ hybridization of control larvae (A,B,D,E,G) and larvae developed from embryos injected with PNA-a9 (C,F,H). (A-F) Anti-Ci-POU IV. (G-H) Anti-Ci-V-Glut probe.

\section{4. miR-9 in Silico Targets Identification}

In order to understand the role of miR-9 in epidermal sensory neuron (ESN) differentiation, we searched for putative targets among genes known to be involved in this process in C. intestinalis [40] and in common pathways of vertebrates [27]. We identified as putative targets of miR-9: (a) Ci-Hes-b (AK174862), Ci-SoxB1 (NM_001128858), and Ci-SoxB2 (NM_001128857), as they are known to regulate ESN differentiation in Ciona [40]; (b) Ci-FoxG (XM_002124957), since its homolog, FoxG1, has been demonstrated to be a specific neural target of miR-9 [41]; (c) Ci-Cadherin (XM_009861227) and Ci-Cadherin 7 (XM_026837209), as miR-9 is the only known miRNA to target E-cadherin transcript in vertebrates [35].

Then, we tested these selected transcripts by bioinformatics analysis. At present, accurate in silico identification of miRNA targets is a great challenge. Numerous programs have been developed to predict putative miRNA targets in vertebrates, Drosophila, and worms (e.g., TargetScan, DIANA, miRANDA, etc.), whereas only a few can be employed in non-standard animal models. In this study, we used 3 free available programs: RNAhybrid [42], RNA22 version 2.0 [43], and PITA executable [44].

We found one or more target sites in all analyzed transcripts. Only considering sites within $3^{\prime}$ UTR, all 3 programs identified the same target site in $C i-F o x G$, whereas 2 programs predicted the same target site in Ci-Hes-b, Ci-caderin, and Ci-SoxB1/2 mRNAs (Table 1). 
Table 1. List of the results obtained from in silico analysis of miR-9 putative targets in C. intestinalis. RNAhybrid, RNA22, and PITA programs. A target was considered valid when found inside the 3'UTR region.

\begin{tabular}{|c|c|c|c|c|c|}
\hline & $3^{\prime}$ UTR & RNAhybrid & RNA22 & PITA & Target Position \\
\hline Ci-Hes-B & $1101 \ldots 1433$ & $X$ & - & $X$ & 1192 \\
\hline Ci-SoxB1 & $1392 \ldots 2584$ & $x$ & - & $X$ & 1468 \\
\hline Ci-SoxB2 & $1136 \ldots 2983$ & $x$ & - & $x$ & 2010 \\
\hline Ci-FoxG & $1742 \ldots 1964$ & $X$ & $x$ & $x$ & 1835 \\
\hline \multirow{2}{*}{ Ci-Cadherin } & \multirow{2}{*}{$2544 \ldots 3215$} & $x$ & $x$ & $x$ & 2558 \\
\hline & & - & - & $x$ & 2791 * \\
\hline Ci-Cadherin 7 & $2837 \ldots 3160$ & $x$ & - & - & 3085 \\
\hline
\end{tabular}

* target site predicted only by PITA.

\section{Discussion}

We explored miR-9 involvement in the $C$. intestinalis development, performing knockdown experiments with antisense peptide nucleic acids (PNAs). PNAs are nucleic acid analogues characterized by a synthetic peptide backbone. These oligomers specifically bind to complementary DNA or RNA sequences, obeying Watson-Crick base paring [11]. In recent years, different studies have demonstrated PNA specificity for their complementary miRNAs in vitro $[4,7,8]$.

In ascidians, recent comparisons between PNAs and the commercial AntagomiRs (Dharmacon, USA) antisense molecules have demonstrated the ability of PNAs to efficiently downregulate miRNAs. The effects induced by injections of these molecules (PNAs and AntagomiRs) into C. intestinalis eggs were comparable, confirming the reliability of PNA-based knockdown [22].

Modified PNAs were also used for sequence-based knockdown mRNA translation through the same morpholino phosphorodiamidate (MO) mechanism of action in zebrafish. Studies comparing the strength of these molecules demonstrated that they were equally effective in downregulating target expression. In addition, PNA oligomers proved to be more specific than conventional MO: even a one-base mismatch in PNA was sufficient to prevent PNA binding with target sequences, while three mismatches were necessary to prevent $\mathrm{MO}$ inhibitory effects [45].

Furthermore, miR-9 is one of the most conserved miRNAs in bilaterian animals, characterized by specific expression in the nervous systems of both vertebrates and invertebrates [27,46,47]. According to our analyses, in the developing nervous system of the ascidian C. intestinalis, mature miR-9 is present in epidermal sensory neurons of the tail and in the papillary sensory neurons. This expression was confirmed using a probe for pri-miRNA. It could be possible that miR-9 is also expressed at low levels in other regions of the developing embryos and cannot be detected by in situ hybridization. We found that downregulation of miR-9 by PNA-a9 microinjections in eggs specifically affected the development of the peripheral nervous system (PNS), as demonstrated by in situ hybridization with specific markers. Although quantitative analysis would be necessary to completely confirm PNA-a9 efficiency, the results appear to be highly reliable. Moreover, we never observed the expression of Ci-POU IV, which is required for PNS specification, in the epidermis of the tail and the trunk of injected embryos.

The PNS of ascidian larvae is composed of a limited number of epidermal sensory neurons (ESNs) located in the trunk and in the tail midline. These ciliated neurons are thought to have mechanosensory functions. In the tail, dorsal and ventral ESNs arise from two separate populations of cells with partially different gene circuits $[40,48,49]$. The tail epidermis midline is a neurogenic region and the Notch pathway negatively controls the number of cells adopting the ESN fate [48]. Subsequently, the sequential activation of MyT1, POU IV, atonal, and NeuroD induces ESN development. Larvae injected with PNA-a9 showed few or no differentiated ESNs. It could be hypothesized that downregulation of miR-9 repressed neural fate determination, as it inhibited neural differentiation by ectopic expression of some of its targets. 
Two inhibitory mechanisms have been proposed for preventing ESN formation; one involving Notch effector genes, such as those belonging to Hes transcriptional repressor family, and the other through SoxB2 gene activation [40]. Our bioinformatics analysis indicated that Hes is a putative target of miR-9 in C. intestinalis, differing from the results of Spina et al. (2011), who did not identify binding sites for miR-9 in any members of the Notch pathway. Interestingly, a set of miR-9 targets are members of the Hes gene family in vertebrates, where they inhibit neural differentiation by repressing proneural genes [27]. The C. intestinalis genome contains three Hes genes (Hes-a, Hes- $b, \mathrm{Hes}-c)$ with different patterns of expression [40,50]. Particularly, Hes- $b$ is expressed outside the epidermis midlines, probably preventing ESN formation [40]. Downregulation of miR-9 could induce Hes- $b$ ectopic expression in the midline, thus inhibiting PNS differentiation in this region. SoxB2 is also a putative target identified by our analysis, and it is expressed throughout the epidermis but not in the midlines. Although few studies are available about this gene in ascidians, it has been demonstrated that $M s x B$ knockdown caused SoxB2 upregulation in the dorsal midline [51]. Moreover, in C. intestinalis, SoxB2 transcripts have been found to be a target of miR-124, another essential neural miRNA, suggesting that its downregulation is necessary to allow nervous system differentiation $[40,52]$.

It is known that miR-9 is the only predicted miRNA to target E-cadherin transcripts in vertebrates [35]. This transmembrane glycoprotein forms the core of cellular adherens junctions and sequesters $\beta$-catenin from the cytoplasm. In $C$. intestinalis, cadherin superfamily genes have been characterized and include 2 classical cadherins: Cadherin and Cadherin II [53]. Our in silico investigations revealed that Cadherin, but not Cadherin II, could also be a possible target of miR-9 in ascidians. In addition, it has been reported that Cadherin overexpression decreases the cytoplasmatic and nuclear levels of $\beta$-catenin, a transcription factor involved in endoderm specification. Disturbance in endoderm differentiation has been demonstrated to lead to differentiation of excess epidermis cells [54]. Thus, miR-9 could also act through Wnt pathways, participating in cell fate determination during ESN development.

Both bioinformatics programs used in this study predicted the same miR-9 target site in the FoxG (the forkhead transcription factor) transcript. Among tetrapods, the miR-9 target sequence at FoxG1 3'UTR (previously called BF-1) is highly conserved [41]. This gene is present in the C. intestinalis genome, however no data are available about FoxG expression and functions. In vertebrates, it is expressed in the telencephalic region of the neural plate and its expression persists in the adult telencephalon. During embryonic development, it has been shown to be essential in driving ventral telencephalic fate downstream of $\mathrm{Hh} / \mathrm{Fgf}$ pathways and controlling the extent of the dorsal compartment through direct transcriptional repression of Wnt ligands [55]. In the cephalochordate, amphioxus AmphiBF-1 expression has been characterized, and notably, at 3 days of development, it is expressed in the anterior-ventral part of the cerebral vesicle [56]. Conservation of the FoxG1 expression pattern in cephalochordates and vertebrates suggests that this gene and its regulatory network could be evolutionarily conserved. However, the $C$. intestinalis FoxG target sequence shows only partial similarities with vertebrates, and further specific analyses are needed to solve this hypothesis.

Overall, our results showed miR-9 involvement in ascidian neural development, further underlining the evolutionary conservation of both miRNA sequences and miRNA-mediated post-transcriptional pathways between vertebrates and ascidians, which have already been suggested by other authors $[40,52]$. In addition, we described in vivo biological activity of a PNA oligomer directed against the miRNA-9 in C. intestinalis embryos. Our results suggest that anti-miR PNA-a9 is able to reach its specific target in the developing ascidian embryos with high efficiency, as underlined by the lack of effect induced by the scrambled sequence. This is further evidence that an unmodified PNA can be successfully used in knockdown strategies in the multicellular organisms of ascidian larvae. 


\section{Materials and Methods}

\subsection{Synthesis and Characterization of PNAs}

PNA-a9 and PNA-sc9 were synthesized by manual solid-phase synthesis using Boc/Z chemistry [57]. The commercially available Boc/Z-protected PNA monomers were purchased from ASM Research Chemicals GmbH (Hannover, Germany). The MBHA resin was purchased from VWR International (Milan, Italy), and it was loaded manually to $0.2 \mathrm{mmol} / \mathrm{g}$ with Boc/Z-adenine PNA monomer for PNA-a9 and with Boc-thymine PNA monomer for PNA-sc9, following the previous procedure [58]. The PNA purification was performed by reverse-phase RP-HPLC with an Agilent 1200 Series system, equipped with a diode array detector (UV detection at $260 \mathrm{~nm}$ ). The purity of PNA-a9 and PNA-sc9 was checked by RP-HPLC analyses, and their identities were confirmed by MALDI-TOF mass spectra, which were recorded with a Bruker Daltonics Omniflex (Milan, Italy), equipped with a $337 \mathrm{~nm}$ pulsed nitrogen laser (sinapinic acid as matrix). PNA-a9 calculated $\mathrm{MW}$ for $\mathrm{C}_{216} \mathrm{H}_{266} \mathrm{~N}_{124} \mathrm{O}_{53}$ : 5447.2; MALDI-TOF MS found $m / z 5448.6[\mathrm{M}+\mathrm{H}]^{+}$. PNA-sc9 calculated MW for $\mathrm{C}_{216} \mathrm{H}_{266} \mathrm{~N}_{124} \mathrm{O}_{53}$ : 5447.2; MALDI-TOF MS found $m / z 5448.4[\mathrm{M}+\mathrm{H}]^{+}$.

\subsection{Animals and Embryos Microinjections}

Ciona intestinalis adults were collected along the coasts of Roscoff by the fishing service of the Roscoff Biological Station (Roscoff, France). Animals were maintained in aquaria filled with artificial sea water (Instant Ocean; salinity about 32\%o) and provided with a circulation system, as well as mechanical, chemical, and biological filters. Constant light condition was preferred to promote gamete production. Gametes from three adults were obtained surgically from the gonoducts and reared in artificial sea water buffered with $1 \mathrm{M}$ HEPES (ASWH; $\mathrm{pH} 8.0$ ) at $18 \pm 1^{\circ} \mathrm{C}$ until the stages of interest. Before being fixed in $4 \%$ paraformaldehyde, $0.5 \mathrm{M} \mathrm{NaCl}$, and $0.1 \mathrm{M} 3$-(N-morpholino)propanesulfonic acid, embryos at gastrula, neurula, and tailbud stages were dechorionated in ASW containing $1 \%$ sodium thioglycolate and $0.05 \%$ protease.

For PNA microinjections, only batches in which $90 \%$ or more of the eggs developed normally were used. Dechorionated eggs were microinjected with solutions of $0.7 \mathrm{mM}$ and $1 \mathrm{mM}$ PNAs (PNA-a9 and PNA-sc9) in distilled water, plus $5 \mu \mathrm{g} / \mu \mathrm{L}$ Fast Green as the vital dye, as described previously [59]. In vitro cross-fertilization was performed and embryos were reared at $16{ }^{\circ} \mathrm{C}$ in a $1 \%$ agarose-coated petri dish in ASW until they reached late tailbud and larva stages (16 and $22 \mathrm{~h}$ post fertilization) [60].

\subsection{In Situ Hybridization}

To describe Cin-miR-9 (MIMAT0016396) expression during C. intestinalis development, in situ hybridization with a DIG-labeled locked nucleic acid (LNA; Exiqon, Vedbaek, Denmark) probe (cin-miR-9: 5'-TCAAACTGGATAACCAAAGA/3Dig_N; DNA Tm $=74{ }^{\circ} \mathrm{C}$ ) was carried out as described before [22].

To confirm the result, a DIG riboprobe specific for pri-miR-9 was also synthetized. First, a PCR product of 578 bp was amplified from C. intestinalis genomic DNA using 5'-TACTGGAGCGTGTTAGGTTTATTG-3' and 5' -AGGGATGCCATGATTAGTAGTGAC-3' as forward and reverse primers, respectively. Then, a fragment of $357 \mathrm{bp}$ was obtained by performing a nested PCR with 5'-AACAACGGCCGTATTGCTTT-3' (forward) and 5'-ACCCCAAATGCTGTTTCGTG-3' (reverse). After cloning with TOPO TA Cloning Kit (Thermo Fisher Scientific, Milan, Italy), DIG-labelled antisense and sense riboprobes were transcribed with Sp6 and T7 RNA polymerase, using a DIG RNA labelling kit (Roche, Monza, Italy).

Standard in situ hybridizations with riboprobes were performed [61]. To characterize the effects of PNA injections, the following neural marker genes were employed: Ci-Pans [37], Ci-POU IV [38], and $\mathrm{Ci}-\mathrm{V}$-Glut [39]. For each probe, at least 25 injected and control embryos were analyzed. For each experimental group, the percentages of samples with abnormal expression were calculated as (number of samples with altered expression / total number of analyzed samples) $\times 100$. 


\section{4. miR-9 Target Prediction}

Based on literature [27,40], we identified Ci-Hes-b (AK174862), Ci-SoxB1 (NM_001128858), Ci-SoxB2 (NM_001128857), Ci-FoxG (XM_002124957), Ci-Cadherin (XM_009861227), and Ci-Cadherin 7 (XM_026837209) as potential neural targets of miR-9. We used three target prediction programs, namely RNAhybrid [42], RNA22 version 2.0 [43], and PITA executable [44], in order to increase the accuracy of target identification. Bioinformatic algorithms were run with default parameters. Transcripts with a binding site in the $3^{\prime}$-UTR region found by one of the bioinformatic algorithms were considered putative miR-9 targets.

Author Contributions: Conceptualization, S.M. and S.C. (Silvia Cauteruccio); ascidian manipulation and investigation, S.M., R.M., and R.P.; methodology, G.S.; PNA synthesis, S.C. (Silvia Cauteruccio); writing-original draft preparation, S.M.; writing-review and editing, S.C. (Silvia Cauteruccio), S.C. (Simona Candiani), and R.P.; supervision, E.L. and R.P.; project administration, E.L. and R.P.; funding acquisition, E.L. and R.P. All authors have read and agreed to the published version of the manuscript.

Funding: This research was supported by Fondazione Cariplo, project 2013-0752.

Conflicts of Interest: The authors declare no conflict of interest.

\section{Abbreviations}

Boc
MALDI-TOF
MBHA
RP-HPLC
Z

tert-Butyloxycarbonyl

Matrix-assisted laser desorption/ionization time-of-flight 4-Methylbenzhydrylamine hydrochloride Reverse-phase high-pressure liquid chromatography Benzyloxycarbonyl

\section{References}

1. Gebert, L.F.R.; MacRae, I.J. Regulation of microRNA function in animals. Nat. Rev. Mol. Cell Biol. 2019, 20, 21-37. [CrossRef]

2. Wahid, F.; Shehzad, A.; Khan, T.; Kim, Y.Y. MicroRNAs: Synthesis, mechanism, function, and recent clinical trials. Biochim. Biophys. Acta 2010, 1803, 1231-1243. [CrossRef]

3. Ardekani, A.M.; Naeini, M.M. The Role of MicroRNAs in Human Diseases. Avicenna J. Med. Biotechnol. 2010, 2, 161-179.

4. Piva, R.; Spandidos, D.A.; Gambari, R. From microRNA functions to microRNA therapeutics: Novel targets and novel drugs in breast cancer research and treatment. Int. J. Oncol. 2013, 43, 985-994. [CrossRef]

5. Chen, Y.; Gao, D.-Y.; Huang, L. In vivo delivery of miRNAs for cancer therapy: Challenges and strategies. Adv. Drug Deliv. Rev. 2015, 81, 128-141. [CrossRef]

6. Rupaimoole, R.; Slack, F.J. MicroRNA therapeutics: Towards a new era for the management of cancer and other diseases. Nature Rev. Drug Discov. 2017, 16, 203-222. [CrossRef]

7. Fabbri, E.; Manicardi, A.; Tedeschi, T.; Sforza, S.; Bianchi, N.; Brognara, E.; Finotti, A.; Breveglieri, G.; Borgatti, M.; Corradini, R.; et al. Modulation of the Biological Activity of microRNA-210 with Peptide Nucleic Acids (PNAs). ChemMedChem 2011, 6, 2192-2202. [CrossRef] [PubMed]

8. Gambari, R.; Fabbri, E.; Borgatti, M.; Lampronti, I.; Finotti, A.; Brognara, E.; Bianchi, N.; Manicardi, A.; Marchelli, R.; Corradini, R. Targeting microRNAs involved in human diseases: A novel approach for modification of gene expression and drug development. Biochem. Pharmacol. 2011, 82, 1416-1429. [CrossRef] [PubMed]

9. Nielsen, P.; Egholm, M.; Berg, R.; Buchardt, O. Sequence-selective recognition of DNA by strand displacement with a thymine-substituted polyamide. Science 1991, 254, 1497-1500. [CrossRef] [PubMed]

10. Nielsen, P.E.; Egholm, M.; Buchardt, O. Peptide nucleic acid (PNA). A DNA mimic with a peptide backbone. Bioconjugate Chem. 1994, 5, 3-7. [CrossRef]

11. Egholm, M.; Buchardt, O.; Christensen, L.; Behrens, C.; Freier, S.M.; Driver, D.A.; Berg, R.H.; Kim, S.K.; Norden, B.; Nielsen, P.E. PNA hybridizes to complementary oligonucleotides obeying the Watson-Crick hydrogen-bonding rules. Nature 1993, 365, 566-568. [CrossRef] [PubMed] 
12. Karkare, S.; Bhatnagar, D. Promising nucleic acid analogs and mimics: Characteristic features and applications of PNA, LNA, and morpholino. Appl. Microbiol. Biot. 2006, 71, 575-586. [CrossRef] [PubMed]

13. Montazersaheb, S.; Hejazi, M.S.; Nozad Charoudeh, H. Potential of Peptide Nucleic Acids in Future Therapeutic Applications. Adv. Pharm. Bull. 2018, 8, 551-563. [CrossRef]

14. Milani, R.; Brognara, E.; Fabbri, E.; Manicardi, A.; Corradini, R.; Finotti, A.; Gasparello, J.; Borgatti, M.; Cosenza, L.C.; Lampronti, I.; et al. Targeting miR-155-5p and miR-221-3p by peptide nucleic acids induces caspase-3 activation and apoptosis in temozolomide-resistant T98G glioma cells. Int. J. Oncol. 2019, 55, 59-68. [CrossRef] [PubMed]

15. Saadati, A.; Hassanpour, S.; Guardia, M.d.l.; Mosafer, J.; Hashemzaei, M.; Mokhtarzadeh, A.; Baradaran, B. Recent advances on application of peptide nucleic acids as a bioreceptor in biosensors development. $\operatorname{Tr} A C$ Trends Anal. Chem. 2019, 114, 56-68. [CrossRef]

16. Saarbach, J.; Sabale, P.M.; Winssinger, N. Peptide nucleic acid (PNA) and its applications in chemical biology, diagnostics, and therapeutics. Curr. Opin. Chem. Biol. 2019, 52, 112-124. [CrossRef]

17. Soudah, T.; Khawaled, S.; Aqeilan, R.I.; Yavin, E. AntimiR-155 cyclic peptide-PNA conjugate: Synthesis, cellular uptake, and biological activity. ACS Omega 2019, 4, 13954-13961. [CrossRef]

18. Gupta, A.; Quijano, E.; Liu, Y.; Bahal, R.; Scanlon, S.E.; Song, E.; Hsieh, W.-C.; Braddock, D.E.; Ly, D.H.; Saltzman, W.M.; et al. Anti-tumor activity of miniPEG-g-modified PNAs to inhibit microRNA-210 for cancer therapy. Mol. Ther. Nucleic Acids 2017, 9, 111-119. [CrossRef]

19. Sajadimajd, S.; Yazdanparast, R.; Akram, S. Involvement of Numb-mediated HIF-1 alpha inhibition in antiproliferative effect of PNA-antimiR-182 in trastuzumab-sensitive and resistant SKBR3 cells. Tumor Biol. 2016, 37, 5413-5426. [CrossRef]

20. Cheng, C.J.; Bahal, R.; Babar, I.A.; Pincus, Z.; Barrera, F.; Liu, C.; Svoronos, A.; Braddock, D.T.; Glazer, P.M.; Engelman, D.M.; et al. MicroRNA silencing for cancer therapy targeted to the tumour microenvironment. Nature 2015, 518, 107-110. [CrossRef]

21. Fabani, M.M.; Abreu-Goodger, C.; Williams, D.; Lyons, P.A.; Torres, A.G.; Smith, K.G.; Enright, A.J.; Gait, M.J.; Vigorito, E. Efficient inhibition of miR-155 function in vivo by peptide nucleic acids. Nucleic Acids Res. 2010, 38, 4466-4475. [CrossRef] [PubMed]

22. Mercurio, S.; Cauteruccio, S.; Manenti, R.; Candiani, S.; Scarì, G.; Licandro, E.; Pennati, R. miR-7 Knockdown by Peptide Nucleic Acids in the Ascidian Ciona intestinalis. Int. J. Mol. Sci. 2019, 20, 5127. [CrossRef] [PubMed]

23. Passamaneck, Y.J.; Di Gregorio, A. Ciona intestinalis: Chordate development made simple. Dev. Dyn. 2005, 233, 1-19. [CrossRef]

24. Cao, C.; Lemaire, L.A.; Wang, W.; Yoon, P.H.; Choi, Y.A.; Parsons, L.R.; Matese, J.C.; Wang, W.; Levine, M.; Chen, K. Comprehensive single-cell transcriptome lineages of a proto-vertebrate. Nature 2019, 571, 349-354. [CrossRef] [PubMed]

25. Dehal, P.; Satou, Y.; Campbell, R.K.; Chapman, J.; Degnan, B.; De Tomaso, A.; Davidson, B.; Di Gregorio, A.; Gelpke, M.; Goodstein, D.M.; et al. The draft genome of Ciona intestinalis: Insights into chordate and vertebrate origins. Science 2002, 298, 2157-2167. [CrossRef]

26. Hendrix, D.; Levine, M.; Shi, W. miRTRAP, a computational method for the systematic identification of miRNAs from high throughput sequencing data. Genome Biol. 2010, 11, R39. [CrossRef] [PubMed]

27. Coolen, M.; Katz, S.; Bally-Cuif, L. miR-9: A versatile regulator of neurogenesis. Front. Cell. Neurosci. 2013, 7, 220. [CrossRef]

28. Brunetti, R.; Gissi, C.; Pennati, R.; Caicci, F.; Gasparini, F.; Manni, L. Morphological evidence that the molecularly determined Ciona intestinalis type A and type B are different species: Ciona robusta and Ciona intestinalis. J. Zool. Syst. Evol. Res. 2015, 53, 186-193. [CrossRef]

29. Spina, E.J.; Guzman, E.; Zhou, H.; Kosik, K.S.; Smith, W.C. A microRNA-mRNA expression network during oral siphon regeneration in Ciona. Development 2017, 144, 1787-1797. [CrossRef]

30. Shibata, M.; Nakao, H.; Kiyonari, H.; Abe, T.; Aizawa, S. MicroRNA-9 Regulates Neurogenesis in Mouse Telencephalon by Targeting Multiple Transcription Factors. J. Neurosci. 2011, 31, 3407-3422. [CrossRef]

31. Li, Y.; Wang, F.; Lee, J.-A.; Gao, F.-B. MicroRNA-9a ensures the precise specification of sensory organ precursors in Drosophila. Genes Dev. 2006, 20, 2793-2805. [CrossRef] [PubMed] 
32. Rajasethupathy, P.; Fiumara, F.; Sheridan, R.; Betel, D.; Puthanveettil, S.V.; Russo, J.J.; Sander, C.; Tuschl, T.; Kandel, E. Characterization of Small RNAs in Aplysia Reveals a Role for miR-124 in Constraining Synaptic Plasticity through CREB. Neuron 2009, 63, 803-817. [CrossRef] [PubMed]

33. Lukiw, W.J. Micro-RNA speciation in fetal, adult and Alzheimer's disease hippocampus. NeuroReport 2007, 18, 297-300. [CrossRef] [PubMed]

34. Packer, A.N.; Xing, Y.; Harper, S.Q.; Jones, L.; Davidson, B.L. The Bifunctional microRNA miR-9/miR-9* Regulates REST and CoREST and Is Downregulated in Huntington's Disease. J. Neurosci. 2008, 28, 14341-14346. [CrossRef] [PubMed]

35. Ma, L.; Young, J.; Prabhala, H.; Pan, E.; Mestdagh, P.; Muth, D.; Teruya-Feldstein, J.; Reinhardt, F.; Onder, T.T.; Valastyan, S.; et al. miR-9, a MYC/MYCN-activated microRNA, regulates E-cadherin and cancer metastasis. Nature Cell Biol. 2010, 12, 247-256. [CrossRef] [PubMed]

36. Khafaei, M.; Rezaie, E.; Mohammadi, A.; Shahnazi Gerdehsang, P.; Ghavidel, S.; Kadkhoda, S.; Zorrieh Zahra, A.; Forouzanfar, N.; Arabameri, H.; Tavallaie, M. miR-9: From function to therapeutic potential in cancer. J. Cell. Physiol. 2019, 234, 14651-14665. [CrossRef]

37. Alfano, C.; Russo, M.T.; Spagnuolo, A. Developmental expression and transcriptional regulation of Ci-Pans, a novel neural marker gene of the ascidian, Ciona intestinalis. Gene 2007, 406, 36-41. [CrossRef]

38. Candiani, S.; Pennati, R.; Oliveri, D.; Locascio, A.; Branno, M.; Castagnola, P.; Pestarino, M.; De Bernardi, F. Ci-POU-IV expression identifies PNS neurons in embryos and larvae of the ascidian Ciona intestinalis. Dev. Genes Evol. 2005, 215, 41-45. [CrossRef]

39. Horie, T.; Kusakabe, T.; Tsuda, M. Glutamatergic networks in the Ciona intestinalis larva. J. Comp. Neurol. 2008, 508, 249-263. [CrossRef]

40. Joyce Tang, W.; Chen, J.S.; Zeller, R.W. Transcriptional regulation of the peripheral nervous system in Ciona intestinalis. Dev. Biol. 2013, 378, 183-193. [CrossRef]

41. Shibata, M.; Kurokawa, D.; Nakao, H.; Ohmura, T.; Aizawa, S. MicroRNA-9 Modulates Cajal-Retzius Cell Differentiation by Suppressing Foxg1 Expression in Mouse Medial Pallium. J. Neurosci. 2008, 28, 10415-10421. [CrossRef] [PubMed]

42. Krüger, J.; Rehmsmeier, M. RNAhybrid: microRNA target prediction easy, fast and flexible. Nucleic Acids Res. 2006, 34, W451-W454. [CrossRef] [PubMed]

43. Miranda, K.C.; Huynh, T.; Tay, Y.; Ang, Y.-S.; Tam, W.-L.; Thomson, A.M.; Lim, B.; Rigoutsos, I. A Pattern-Based Method for the Identification of MicroRNA Binding Sites and Their Corresponding Heteroduplexes. Cell 2006, 126, 1203-1217. [CrossRef] [PubMed]

44. Kertesz, M.; Iovino, N.; Unnerstall, U.; Gaul, U.; Segal, E. The role of site accessibility in microRNA target recognition. Nat. Genet. 2007, 10, 1278-1284. [CrossRef] [PubMed]

45. Duffy, K.T.; McAleer, M.F.; Davidson, W.R.; Kari, L.; Kari, C.; Liu, C.-G.; Farber, S.A.; Cheng, K.C.; Mest, J.R.; Wickstrom, E.; et al. Coordinate control of cell cycle regulatory genes in zebrafish development tested by cyclin D1 knockdown with morpholino phosphorodiamidates and hydroxyprolyl-phosphono peptide nucleic acids. Nucleic Acids Res. 2005, 33, 4914-4921. [CrossRef]

46. Candiani, S. Focus on miRNAs evolution: A perspective from amphioxus. Brief. Funct. Genom. 2012, 11, 107-117. [CrossRef]

47. Candiani, S.; Moronti, L.; De Pietri Tonelli, D.; Garbarino, G.; Pestarino, M. A study of neural-related microRNAs in the developing amphioxus. EvoDevo 2011, 2, 15. [CrossRef]

48. Pasini, A.; Amiel, A.; Rothbächer, U.; Roure, A.; Lemaire, P.; Darras, S. Formation of the Ascidian Epidermal Sensory Neurons: Insights into the Origin of the Chordate Peripheral Nervous System. PLoS Biol. 2006, 4, e225. [CrossRef]

49. Waki, K.; Imai, K.S.; Satou, Y. Genetic pathways for differentiation of the peripheral nervous system in ascidians. Nat. Commun. 2015, 6, 8719. [CrossRef]

50. Imai, K.S.; Hino, K.; Yagi, K.; Satoh, N.; Satou, Y. Gene expression profiles of transcription factors and signaling molecules in the ascidian embryo: Towards a comprehensive understanding of gene networks. Development 2004, 131, 4047-4058. [CrossRef]

51. Imai, K.S.; Levine, M.; Satoh, N.; Satou, Y. Regulatory Blueprint for a Chordate Embryo. Science 2006, 312, 1183-1187. [CrossRef] 
52. Chen, J.S.; Pedro, M.S.; Zeller, R.W. miR-124 function during Ciona intestinalis neuronal development includes extensive interaction with the Notch signaling pathway. Development 2011, 138, 4943-4953. [CrossRef] [PubMed]

53. Noda, T.; Satoh, N. A comprehensive survey of cadherin superfamily gene expression patterns in Ciona intestinalis. Gene Expr. Patterns 2008, 8, 349-356. [CrossRef] [PubMed]

54. Imai, K.; Takada, N.; Satoh, N.; Satou, Y. (beta)-catenin mediates the specification of endoderm cells in ascidian embryos. Development 2000, 127, 3009-3020. [PubMed]

55. Danesin, C.; Houart, C. A Fox stops the Wnt: Implications for forebrain development and diseases. Curr. Opin. Genet. Dev. 2012, 22, 323-330. [CrossRef]

56. Toresson, H.; Martínez-Barberá, J.P.; Bardsley, A.; Caubit, X.; Krauss, S. Conservation of BF-1 expression in amphioxus and zebrafish suggests evolutionary ancestry of anterior cell types that contribute to the vertebrate telencephalon. Dev. Gene Evol. 1998, 208, 431-439. [CrossRef]

57. Nielsen, P.E. Peptide Nucleic Acids: Protocols and Applications, 2nd ed.; Horizon Bioscience: Copenhagen, Denmark, 2004.

58. Prencipe, G.; Maiorana, S.; Verderio, P.; Colombo, M.; Fermo, P.; Caneva, E.; Prosperi, D.; Licandro, E. Magnetic peptide nucleic acids for DNA targeting. Chem. Commun. 2009, 40, 6017-6019. [CrossRef]

59. Kari, W.; Zeng, F.; Zitzelsberger, L.; Will, J.; Rothbächer, U. Embryo Microinjection and Electroporation in the Chordate Ciona intestinalis. J. Vis. Exp. 2016, 116, e54313. [CrossRef]

60. Hotta, K.; Mitsuhara, K.; Takahashi, H.; Inaba, K.; Oka, K.; Gojobori, T.; Ikeo, K. A web-based interactive developmental table for the ascidian Ciona intestinalis, including 3D real-image embryo reconstructions: I. From fertilized egg to hatching larva. Dev. Dyn. 2007, 236, 1790-1805. [CrossRef]

61. Messinetti, S.; Mercurio, S.; Pennati, R. Bisphenol A affects neural development of the ascidian Ciona robusta. J. Exp. Zool. 2019, 331, 5-16. [CrossRef]

(C) 2020 by the authors. Licensee MDPI, Basel, Switzerland. This article is an open access article distributed under the terms and conditions of the Creative Commons Attribution (CC BY) license (http://creativecommons.org/licenses/by/4.0/). 